\section{AUS DEN VERBÅNDEN}

\section{Bayerische Regierung ignoriert den Willen der Pflegenden}

CSU und SPD haben, trotz eines massiven Protests und nur einen Tag nach der großen Pflege-Demonstration, einen Antrag der Freien Wähler zur Gründung einer Pflegekammer im Bayerischen Landtag abgeschmettert. Damit ignoriert die Bayerische Regierung den Willen der professionell Pflegenden und missachtet demokratische Prinzipien. Lautstark hatten sich Pflegende bei der großen Demonstration am Münchner Odeonsplatz für eine Pflegekammer ausgesprochen. Das war ein deutliches Signal an die Politik. Sie wehrten sich damit gegen den vom bayrischen Gesundheitsministerium propagierten Vorschlag, in Bayern eine Interessensvertretung auf freiwilliger Basis zu installieren. Diese wird nun offenbar ohne Zustimmung der Pflegeverbände und trotz des massiven Protestes durchgesetzt. Die Regierung setzt sich damit über den Willen der professionell Pflegenden hinweg und das, obwohl sich in der repräsentativen Umfrage die Pflegefachpersonen mit über $50 \%$ für eine Pflegekammer ausgesprochen hatten. Der DBfK setzt sich weiterhin für einen gemeinsamen Weg zusammen mit der Politik ein. Eine Interessensvertretung jedoch, wie es dem Ministerium vorschwebt, wird die Probleme in der Pflege und den extremen Fachpersonenmangel nicht lösen. Die Herausforderungen in der Pflege sind gewaltig. Sie können ohne die Expertise der Berufsgruppe nicht gemeistert werden.

\section{Dr. Marliese Biederbeck}

DBfK-Geschäftsführerin

\section{Impressum}

Herausgeber: Deutscher Pflegerat (DPR) Bundesarbeitsgemeinschaft Pflege- und Hebammenwesen Inhalt: Claudia Dachs (verantwortlich) Alt-Moabit 91, 10559 Berlin

("Haus der Gesundheitsberufe")

Tel.: 03039877 303; Fax 03039877304 www.deutscher-pflegerat.de

„PflegePositionen“ - Der offizielle Newsletter des DPR erscheint in Kooperation mit HEILBERUFE - Das Pflegemagazin.

Verlag: Springer Medizin Verlag GmbH Heidelberger Platz 3, 14197 Berlin

Tel.: 030 827875500, Fax: 030827875505

Director Professional Care: Falk H. Miekley

Chefredakteurin: Katja Kupfer-Geißler Heidelberger Platz 3, 14197 Berlin

Tel.: 03082787 5500, Fax: 030827875505

www.heilberufe.de

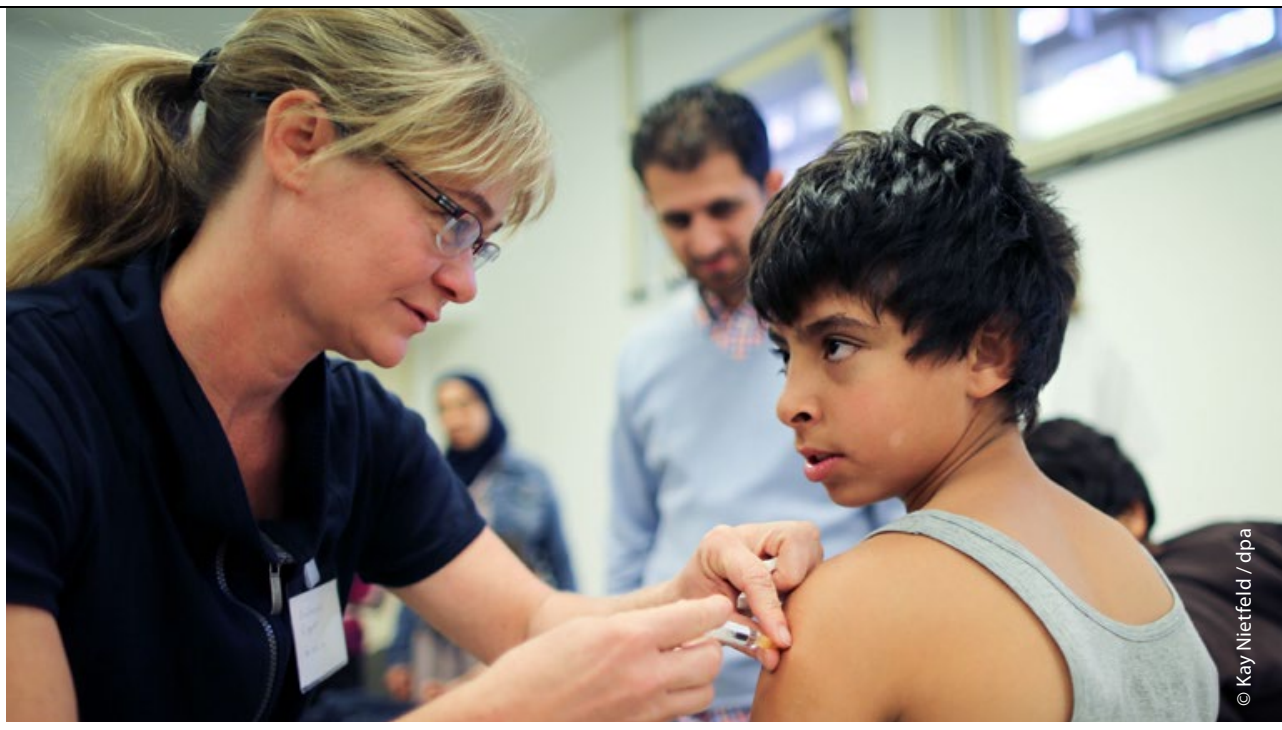

Aufruf des DPR

\title{
Flüchtlinge brauchen noch lange unsere Hilfe
}

Beruflich Pflegende leisten bei der Versorgung der Flüchtlinge großartige Arbeit. Der Deutsche Pflegerat dankt daher allen Freiwilligen und beruflich Pflegenden für ihre hervorragende Leistung bei der Versorgung der Flüchtlinge und ruft auf, mit der Unterstützung nicht nachzulassen.

$\mathrm{S}$ ie helfen - ohne große Worte, direkt und unmittelbar. Damit spiegeln die professionell Pflegenden das wider, was unseren Beruf besonders auszeichnet und wertschätzt.

\section{Für eine humane Hilfe eintreten}

Der Deutsche Pflegerat bittet, mit der Unterstützung nicht nachzulassen, denn die Flüchtlinge brauchen noch lange unsere Hilfe. Als professionell Pflegende sind wir dabei besonders gefragt, denn auch Flüchtlinge benötigen eine gute gesundheitliche Versorgung.

Die professionelle Pflege ist dem Schutz aller Menschen und der respektvollen Achtung der Menschenrechte verpflichtet. Als Deutscher Pflegerat treten wir für eine humane und den pflege- und hilfebedürftigen Menschen in den Mittelpunkt stellende Hilfe ein. Darin liegt auch unsere grundlegende Verantwortung. Wir rufen daher alle professionell
Pflegenden sowie Gesundheits- und Pflegeeinrichtungen dazu auf, sich gegen jede Art von menschenverachtendem Gedankengut zu stellen.

\section{Schulungen für die Helfer}

Aus den bisherigen Erfahrungen ist deutlich geworden, dass die gesundheitliche Versorgung der Flüchtlinge die Gesundheitsprofessionen und Institutionen, wie Krankenhäuser, vor große Herausforderungen stellt. Es bedarf unter anderem spezieller Kenntnisse zur Versorgung dieser Menschen. Wir brauchen deshalb entsprechende Schulungen der Helfer. Zudem gestaltet sich die Kostenübernahme erbrachter medizinischer und pflegerischer Leistungen häufig schwierig. Schnelle und unbürokratische Lösungen müssen gefunden werden.

\section{Franz Wagner}

Vize-Präsident des Deutschen Pflegerats 